\title{
Prevalence and risk factors associated with Myopia among MBBS students of a private medical college in Central Kerala
}

\author{
Nirmala ${ }^{1}$, Krishnan $G^{2}$, Antharjanam $D^{3}$, Harsha C.H ${ }^{4}$, Mary Ann ${ }^{5}$, Londhe $S^{6}$, Antony $R^{7}$ \\ ${ }^{1}$ Dr. Nirmala, Department of Ophthalmology, ${ }^{2}$ Dr Gopalakrishnan P, Associate Professor, Department of Community \\ Medicine, ${ }^{3}$ Dr Devaki Antharjanam, Assistant Professor, Department of Community Medicine, ${ }^{4}$ Ms Harsha C.H, \\ Assistant Professor, Bio-Statistics, Department of Community Medicine, ${ }^{5}$ Dr. Ann Mary, Assistant Professor, \\ Department of Community Medicine, ${ }^{6}$ Dr. Swathy Londhe, Professor, Department of Community Medicine, \\ ${ }^{7}$ Dr Raju Antony, Professor \& HOD, Department of Community Medicine; all authors are attached with SNIMS, \\ Chalakka, Ernakulam., Kerala, India.
}

Address for Correspondence: Dr. Nirmala, Email: nimma.prabhu@gmail.com

\begin{abstract}
Background Myopia is a common ocular disease. Increasing myopia prevalence rate is posing a threat to the health and economy of the developing countries. Review of literature revealed a strong association of myopia with learned people and the possible role of environmental, nutritional, hereditary and near work in the increased prevalence of myopia. Objective to determine the prevalence of myopia among MBBS students in a private medical college and to find out the possible risk factors associated with the disease. Materials and Methods cross sectional study was conducted among the medical students of a private medical college of central Kerala using a pretested, semi structured questionnaire which was distributed to those who gave consent. The visual acuity of the students who participated was also noted using the Snellens chart. Results Out of 100 students 42 were myopes of which 38 were known cases and 4 were found out during our study. $45.33 \%$ of the female and $32 \%$ of male had myopia. Conclusion Prevalence of Myopia was found to be high among the medical students in this study. Regular eye check up is mandatory in medical students.
\end{abstract}

Key words: Myopia Prevalence, Parental Myopia, Refractive Errors, Risk Factors

\section{Introduction}

Myopia is a type of refractive error in which parallel rays of light are brought to focus in front of the retina when accommodation is at rest, due to which eyes fail to see distant objects properly. The increase in the rate of myopia prevalence is a threat to the health and economy of developing countries. In the ophthalmic literature, there are evidences to support the association of myopia with the level of education. Studies by Kathrina et al found that higher level of educational attainment and post school professional education are associated with myopia [1]. In addition to this environmental changes, nutritional factors, heredity and close work are suggested as the risk factors for the increase in the prevalence of myopia. Sunantha et al conducted a cross sectional study in 2012 in which

Manuscript received $20^{\text {th }}$ May 2016

Reviewed: $3^{\text {rd }}$ June 2016

Author Corrected: $14^{\text {th }}$ June 2016

Accepted for Publication $29^{\text {th }}$ June 2016 myopia was found to be predominant among medical students. They postulated that medical students, who were a select population with a high level of education as well as above average intelligence, were required to undergo a long and intensive course which involved extensive near work such as reading and writing. They suggested that this could be the possible reason for the high prevalence of myopia among medical student [2]. The prevalence varies from $30.3 \%$ in middle aged adults and $35.0 \%$ in young adults in Norway and $53 \%$ in Norwegian medical students [3]. A high myopia prevalence was demonstrated among medical students in the inner Mongolia area of China [4]. The prevalence of myopia in Singapore is one of the highest worldwide. Studies conducted by $\mathrm{Wu} \mathrm{HM}$ et al found that the prevalence and severity of myopia had a strong association with education.[5] Various studies reported that prevalence of myopia among girls was more than 
that of boys [2, 6, 8]. Basu $\mathrm{M}$ et al conducted a cross sectional study among urban female students and found out refractive error was present in $15.22 \%$, of which myopia was most common $(91.7 \%)$ [9].

Several environmental risk factors for myopia, including higher educational attainment, higher socio economic status and increased amount of near-work activities, are well documented in children and adult population. However, the exact mechanism of how these factors induce the development and progression of myopia remains controversial. The use of electronic gadgets such as televisions, mobile phones, laptops, and its impact on the progression of myopia has always been controversial. Chaudhry et al observed in their study that, study hours, watching television, computer working and physical exercise did not show any statistical relationship with myopia [8]. In other studies, high incidence and progression of myopia was associated with environmental factors such as computers, video games, television, mobile phones and genetic factors [6] According to a study conducted to find out risk factors associated with myopia in Taiwan, it was found that myopes used gadgets like computers for 3.82 hours and non myopes for 3.74 hours [10].

The study conducted by Konstantopoulos A et al, DonaldO Mutti et al and Chaudhry et al reported a strong relation between Myopia and heredity [11,12,8]. At present along with cataract, macular degeneration, infectious disease and vitamin A deficiency, myopia too has become one of the most important causes of visual impairment worldwide. Severe or high-grade myopia is a leading cause of blindness because of its associated ocular co-morbidities of retinal detachment, macular choroid degeneration, premature cataract and glaucoma. Ample epidemiologic and molecular genetic studies are also available to support the conclusive evidence that myopia is inherited. With the increased prevalence of myopia, developing countries may face economic problem directly due to disease itself and indirectly due to loss of manpower. With this background a crosssectional study was conducted to find out the prevalence of myopia and its risk factors among the medical students.

\section{Materials and Methods}

An observational cross sectional study was conducted among 100 MBBS students of 2010 and 2011 batches in a private medical college by using convenient sampling method. Research and ethics committee of the institute approved the study design. Informed written consent was obtained from each student after explaining the nature of study to them individually. Instructions were given in the regional language. Pre tested semi structured questionnaire in English was used for data collection. They were asked to fill up the questionnaire and return it immediately. The visual acuity of all students were checked using Snellens chart and 6/6 was taken as normal vision. Data was entered in the Microsoft excel spreadsheet and analyzed using Epi Info version 7 software. Mean, frequencies and percentages were calculated and association between the risk factors and myopia were assessed by using Chisquare test.

\section{Results}

Out of 100 medical students, 75 females and 25 males participated in the study. Mean age of the participants was 21.28 years (Ranges from 19 to 24 years). A total of 42 cases were found to be having Myopia, of which 38 were known cases and 4 were newly detected during the study.

Table-1: Prevalence of Myopia among males and female students.

\begin{tabular}{|c|c|c|c|c|}
\hline \multirow{2}{*}{ Sex } & \multicolumn{2}{|c|}{ Number of students } & \multirow{2}{*}{ Total } & \multirow{2}{*}{ p value } \\
\cline { 2 - 3 } & with Myopia & without Myopia & & \multirow{2}{*}{0.242} \\
\hline Female & $34(45.33 \%)$ & $41(54.66 \%)$ & $75(100 \%)$ & $25(100 \%)$ \\
\hline Male & $8(32 \%)$ & $17(68 \%)$ & 0.242 & \\
\hline
\end{tabular}

Out of 100 students examined, 34 (45.33\%) female students and 8 (32\%) male students were found to be Myopic. But no statistical difference was obtained $(\mathrm{p}=0.242)$

Based on the visual acuity, severity of Myopia was graded as minimal (6/9) mild if $6 / 12$ or $6 / 18$, moderate if $6 / 24$ or $6 / 34$ and severe if $>/=6 / 60$. In the present study there were 4 students $(9.52 \%)$ belonging to minimal grade, 16 students (38.09\% in mild, $30.95 \%$ in moderate and $21.42 \%$ in severe grade of Myopia. 
Table-2: Corrective measures adopted by students with Myopia.

\begin{tabular}{|c|c|c|}
\hline \multirow{2}{*}{ Corrective Measures } & \multicolumn{2}{|c|}{ Students with Myopia } \\
\cline { 2 - 3 } & Number & $13.2 \%$ \\
\hline Contact lens & 5 & $78.9 \%$ \\
\hline Spectacles & 30 & $5.3 \%$ \\
\hline Contact lens and / or Spectacles & 2 & $2.6 \%$ \\
\hline Not using any corrective measures* & $\mathbf{3 8} *$ & $\mathbf{1 0 0 \%}$ \\
\hline Total & 1 & \\
\hline
\end{tabular}

*out of the 42 who were myopic, 4 were newly detected by our study.

Table-3: Time spent daily on reading printed material by students with and without Myopia.

\begin{tabular}{|c|c|c|c|c|}
\hline \multirow{2}{*}{$\begin{array}{c}\text { Reading Hours per } \\
\text { day }\end{array}$} & \multicolumn{2}{|c|}{ Number of Students } & \multirow{2}{*}{ Total } & \multirow[b]{2}{*}{ p value } \\
\hline & with Myopia & without Myopia & & \\
\hline$<3 \mathrm{Hrs}$ & $33(78.6 \%)$ & $52(89.7 \%)$ & 85 & \multirow{3}{*}{0.126} \\
\hline$>3 \mathrm{Hrs}$ & $9(21.4 \%)$ & $6(10.3 \%)$ & 15 & \\
\hline Total & $42(100 \%)$ & $58(100 \%)$ & $100(100 \%)$ & \\
\hline
\end{tabular}

Among the students who spent time daily on reading printed material for $>3 \mathrm{hrs} 9(21.4 \%)$ students were with myopia and $6(10.3 \%)$ were without myopia. However this difference was not statistically significant $(\mathrm{p}=0.126)$

Table-4: Time spent on using electronic gadgets like mobile phones, tablets, music players etc. by students with and without Myopia.

\begin{tabular}{|c|c|c|c|c|}
\hline \multirow{2}{*}{ Time } & \multicolumn{2}{|c|}{ Number of Students } & \multirow{2}{*}{ Total } & p value \\
\cline { 2 - 3 } & with Myopia & without Myopia & 42 & \\
\cline { 1 - 3 }$>60$ minutes & $20(47.6 \%)$ & $22(37.9 \%)$ & 58 & 0.333 \\
\hline Total & $22(52.38 \%)$ & $36(62.06 \%)$ & $\mathbf{1 0 0}$ & \\
\hline
\end{tabular}

Out of the total 58 students, who used electronic devices for $>60$ minutes per day $22(52.38 \%)$ were with Myopia and $36(62.06 \%)$ were without Myopia, showing no association/statistical significance $(\mathrm{p}=0.333)$. (deleted rest of the sentence)

Table-5: Reading distance (eye and reading material) by students with and without Myopia.

\begin{tabular}{|c|c|c|c|c|}
\hline \multirow{2}{*}{ Reading distance } & \multicolumn{2}{|c|}{ Number of Students } & \multirow{2}{*}{ Total } & \multirow{2}{*}{ p value } \\
\cline { 2 - 4 } & with Myopia & without Myopia & 89 & \\
\hline$<30 \mathrm{~cm}$ & $40(95.23 \%)$ & $49(84.4 \%)$ & 11 & 0.155 \\
\hline$=>30 \mathrm{~cm}$ & $2(4.76 \%)$ & $9(15.51 \%)$ & $\mathbf{1 0 0}$ & \\
\hline Total & $\mathbf{4 2 ( 1 0 0 \% )}$ & $\mathbf{5 8 ( 1 0 0 \% )}$ & \\
\hline
\end{tabular}

In the analysis of the usual reading distance of students, we found that in 40 (95.23\%) students with Myopia and 49 (84.4\%) students without Myopia reading distance was $<30 \mathrm{~cm}$ However the difference was not statistically significant $(\mathrm{p}=0.155)$.

Among those students with family history of both parents having myopia, it was noted that myopia was present in 7 (16.7\%) students. No myopia was seen in the parents of 25 (59.5) students who were with myopia. Similarly the analysis was also done with the family history of one parent and none of the parent having myopia. Here also the difference was not statistically significant $(\mathrm{p}=0.729)$. 
Table-6: Association between students and their Parents with Myopia.

\begin{tabular}{|c|c|c|c|c|}
\hline \multirow{2}{*}{ Parents with Myopia } & \multicolumn{2}{|c|}{ Number of Students } & \multirow{2}{*}{ Total } & \multirow[b]{2}{*}{ p value } \\
\hline & with Myopia & without Myopia & & \\
\hline Both parents & $7(16.7 \%)$ & $8(13.8 \%)$ & 15 & \multirow{4}{*}{0.729} \\
\hline One parent & $10(23.8 \%)$ & $11(18.9 \%)$ & 21 & \\
\hline None & $25(59.5 \%)$ & $39(67.2 \%)$ & 64 & \\
\hline Total & $42(100 \%)$ & $58(100 \%)$ & 100 & \\
\hline
\end{tabular}

\section{Discussion}

In our study out of 100 students, 38 were known cases of myopia and 4 were newly found during our study $(42 \%)$. Grades of myopia were minimal $(9.52 \%)$, mild $(38.09 \%)$, moderate $(30.95 \%)$, severe $(21.42 \%)$. High myopia prevalence was demonstrated among medical students in the Inner Mongolia area of China. [4] In a cross-sectional study conducted at Liaquat National Medical College, Karachi prevalence rate was found to be $47 \%$ [13]. Cross-sectional study to determine the prevalence of refractive errors among medical students attending Burdwan Medical College found myopia as the most common type of refractive error $(60.03 \%)$ [14] Study conducted at Melaka Manipal Medical College, Manipal, India prevalence rate of myopia was found to be $80.3 \%$. The medical students belonged to Chinese, Malay and Indians in ethnicity [15]. It is possible that the differences in methodology, non-participation rates, ethnic variations and genetic predispositions might be the reasons for the difference in myopia prevalence rates in medical students across different countries.

In our study regarding gender distribution, prevalence of myopia was more in females $(45.33 \%)$ compared with males (32\%) Study conducted at Karachi also showed a high prevalence of myopia in females (73.4\%) [13] Chaudhary et al also reported an increased prevalence of myopia in females (61\%) [8]. Low compliance with spectacle use had been reported in several studies. In a study done in rural China, one-third of the students were advised to use spectacles and only a quarter of them wore the glasses regularly [16]. Study done by Akhanda $\mathrm{A} \mathrm{H}$ et al on 175 medical students of a college in Bangladesh found that only one quarter (21.6\%) of the myopic students was not using spectacles [17]. Contrary to this the present study showed only 1 student (2.6\%) not using corrective measures.

With regard to the time spent on reading printing material, our study showed that there is no significant relationship with the number of hours spent for reading printed material and the causation of Myopia, Study conducted by Oner $\mathrm{V}$ et al also found that the mean daily time spent on reading and writing and initial refraction value were independently associated with annual myopic progression rate [18]. In a study conducted by N. Praveen et al, reported that among the Myopes $50.2 \%$ had an increase in study duration and $56.3 \%$ complained of worsening of their myopia with the medical studies [13].

Study done by Praveen et al reported that time spent on electronic gadgets was high, $(64.2 \%)$ among the myopes but in our study we found that out of 58 students, $36(62.06 \%)$ students who spent $>1$ hour on electronic gadgets were without myopia and the rest 22 $(52.38 \%)$ were having myopia [13].

In our study, it was found that out of 42 myopic students $16.66 \%$ had a family history of myopia in both parents while out of 58 non-myopics students only $13.8 \%$ had a family history of myopia in both parents $(\mathrm{p}=0.729)$. While in a similar stuy conducted in Lahore by Chaudhry et al $60.7 \%$ had positive family history (myopia among first blood relations), whereas $18.8 \%$ myopics did not show any history. Statistically, it showed strong significant relationship $(p=0.000003)$ [8]. Study conducted by Chung Ling Liang et al showed that a strong family history is associated with high myopia. This can be due to the increase in the axial length [19]. But study conducted by Rafael Iribarren et al showed that family history has no role in myopia of low to moderate degree [20]. In our study only $21 \%$ are having high myopia and the rest are having low to moderate grade, probably this may be the reason for statistically not significant association between myopia and family history.

\section{Conclusion}

Myopia is a significant problem among medical students. From our study it has been found out that a 
significant number of medical students were suffering from myopia. This refractive error can go unnoticed and if timely intervention is not made, it may progress to severe grades. Uncorrected refractive errors impair the quality of life and are the leading cause of visual impairment across the world. It is one of the major causes of avoidable blindness. Detection of four new cases needs to be taken rightly because even among the medical students undetected cases are present. It is therefore advisable that all students should have regular eye check-ups and use appropriate corrective lenses and care should be taken to avoid too much use of electronic gadgets

Acknowledgement-I am thankful to the students of 2010 and 2011 batches, HOD and staff of the community medicine department for extending all support and help for the conduct of this study.

Funding: Nil, Conflict of interest: None initiated, Permission from IRB: Yes

\section{Reference}

1. Katharina A. Ponto, René Hoehn, Isabella Zwiener, Tanja Zeller, Karl Lackner, Manfred E. Beutel, Norbert Pfeiffer, Myopia and Level of Education, Ophthalmology October 2014 Volume 121, Issue 10, Pages 2047-2052.

2. Sunantha Chalasami, Vasantha kumari, Jampala. Myopia among medical students. Al-Ameen Journal of Medical Sciences 2012 vol 5(3):233.

3. Midelfart A, Aamo B, Sjøhaug KA, Dysthe BE. Myopia among medical students in Norway. Acta Ophthalmol (Copenh). 1992 Jun;70(3):317-22.

4. Yanyan $\mathrm{Wu}, \mathrm{He} \mathrm{Yi}$, Wenzhong Liu, Haiying Jia, Yuki Eshita, Shubi Wang, Peng Qin, Juan Sun. Risk factors for myopia in Inner Mongolia medical students in China. Open Journal of Epidemiology, 2012, 2, 8389, Published November 2012

5. Wu HM, Seet B,Yap EP, Saw SM, Lim TH, Chia KS.Does education explain ethnic differences in myopia prevalence? A population-based study of young adult males in Singapore. Optom Vis Sci 2005; 78: 234-9.

6. Ahmed I Mian S, Mudasir S, Andrabi KI. Prevalence of myopia in students of srinagar city of kashmir, India. Int J Health Sci (Qassim). 2008 Jan;2(1):77-81.
7. Wu HM, Seet B, Yap EP, Saw SM, Lim TH, Chia KS.Does education explain ethnic differences in myopia prevalence? A population-based study of young adult males in Singapore.Optom Vis Sci 2005; 78: 234-9.

8. Razia Chaudhry, Hassan Ali, Naheed H Sheikh. Frequency and underlying factors of myopia among medical students. Biomedical vol27 (July-Dec 2011); 154-60.

9. Basu M, Das P, Pal R, Kar S, Desai VK, Kavishwar A. Spectrum of visual impairment among urban female school students of Surat. Indian J Ophthalmol. 2011 Nov-Dec; 59 (6) : 475-9. doi: 10.4103 / 0301 - 4738. 86317.

10. Lee YY, Lo CT, Sheu SJ, Lin JL. What factors are associated with myopia in young adults? A survey study in Taiwan Military Conscripts. Invest Ophthalmol Vis Sci. 2013 Feb 5; 54 (2):1026-33. doi: 10.1167/iovs. 12-10480.

11. Konstantopoulos A, Yadegarfar G, Elgohary M. Near work, education, family history, and myopia in Greek conscripts. Eye (Lond). 2008 Apr;22(4):542-6. Epub 2007 Jan 12.

12. Donald O. Mutti; G. Lynn Mitchell; Melvin L. Moeschberger; Lisa A. Jones; Karla Zadnik: Parental Myopia, Near Work, School Achievement, and Children's Refractive Error Clinical and Epidemiologic Research December 2002, Investigative Ophthalmology \& Visual Science December 2002, Vol.43, 3633-3640.

13. Naila Parveen, Syed Hafeezul Hassan Javeria Rehman, Usman Shoukat prevalence of myopia and its associated risk factors in local medical students medical channel MC Vol. 21 - No.4 - 2015 (47-50).

14. Asim Kumar Dey, Soumen Kumar Chaudhuri, Subhasis Jana, Purban Ganguly, Sumi Ghorai, Ashim Sarkar Prevalence of Refractive Errors in Medical Students. IJHSR. 2014; 4(8): 98-102.

15. Jessica S D, Surekha R Kamath, Alwin Foo Jar Jun, Yuganesh Chandrasegar Study of refractive errors among medical students of Melaka Manipal medical college at Manipal in India BRCORP 4 th World Conference on Applied Sciences, Engineering \& Technology 24-26 October 2015, Kumamoto University, Japan WCSET 2015019. 
16. Li L, Song Y, Liu X, Lu B, Choi K, Lam D S et al. Spectacle acceptance among secondary school students in rural China. The Xichang Paediatric Refractive error study (X-Pres)- Report5. Invest Ophthalmol Vis Sci 2008; 49:2895-902.

17. Akhanda AH, Quayum MA, Siddiqui NI, Hossain MM. Refractive status of medical students of mymensingh medical college. Mymensingh Med J. 2010 Oct;19(4):493-6.

18. Öner V, Bulut A, Oruç Y, Özgür G. Influence of indoor and outdoor activities on progression of myopia during puberty. Int Ophthalmol. 2016 Feb;36(1):121-5. doi: 10.1007/s10792-015-0091-5. Epub 2015 Jun 2.
19. Chung-Ling Liang; Eugene Yen; Jui-Yung Su; Chang Liu; Tzu-Yi Chang; Naeun Park; Ming-Jin Wu; Sharon Lee; John T. Flynn; Suh-Hang Hank Juo Impact of Family History of High Myopia on Level and Onset of Myopia, Investigative Ophthalmology \& Visual Science October 2004, Vol.45, 3446-3452. doi:10. 1167 liovs.03-1058.

20. Rafael Iribarren, Alejandra Balsa, Alejandro Armesto, Tomás Pfortner, Family history of myopia is not related to the final amount of refractive error in low and moderate myopia, Clinical and Experimental Ophthalmology 33(3):274-8. July 2005 DOI: 10.1111 /j.1442-9071.2005.01009.x

\section{How to cite this article?}

Nirmala, Krishnan G, Antharjanam D, Harsha C.H, Mary Ann, Londhe S, Antony R. Prevalence and risk factors associated with Myopia among MBBS students of a private Medical College in Central Kerala.Int J Med Res Rev 2016;4(9):1596-1601.doi:10.17511/ijmrr. 2016.i09.14. 